\title{
A IMPORTÂNCIA DA GOVERNANÇA CORPORATIVA E DO CONTROLE INTERNO NÁ ÁREA CONTÁBIL
}

\author{
THE IMPORTANCE OF CORPORATE GOVERNANCE AND \\ INTERNAL CONTROL IN THE ACCOUNTING AREA
}

\section{Andrea Brasil e Souza}

MBA Auditoria e Contabilidade Digital pela Universidade Feevale (Novo Hamburgo/Brasil)

E-mail: bsouza.andrea@gmail.com

\section{Maristela Mercedes Bauer}

Pós-doutorado em Contabilidade pela Regensburg Universität (Regensburg/Alemanha)

Professora na Universidade Feevale (Novo Hamburgo/Brasil)

E-mail: maristelabauer@feevale.br

Currículo Lattes: http://lattes.cnpq.br/6464555968478614

\section{Luciana Coletti}

Doutora em Filosofia pela Universidade do Vale do Rio dos Sinos (São Leopoldo/Brasil)

Professora na Universidade Feevale (Novo Hamburgo/Brasil)

E-mail: lucianac@feevale.br

Currículo Lattes: http://lattes.cnpq.br/0413372584823352 


\section{RESUMO}

Este estudo tem como objetivo analisar a percepção dos profissionais da área contábil do Vale do Rio do Sinos-RS em relação à importância do controle interno no contexto das boas práticas de governança corporativa. Para tanto, utilizou-se as pesquisas descritiva, bibliográfica, levantamento, com abordagem qualitativa e quantitativa. A coleta de dados foi realizada por meio de questionário, desenvolvido com perguntas abertas e fechadas, com alternativas de simples ou múltipla escolha, aplicados em uma amostra não probabilística por acessibilidade. 0 estudo apontou que os profissionais da área contábil participantes dessa pesquisa percebem que esses controles possuem importância no contexto das boas práticas de governança corporativa, através de seus princípios de transparência, equidade, prestação de contas e responsabilidade corporativa.

Palavras-chave: Governança Corporativa. Controles Internos. Transparência. Contabilidade.

\section{ABSTRACT}

This study aims to analyze the perception of accounting professionals in Vale do Rio do Sinos Rio Grande do Sul State in relation to the importance of internal control in the context of good corporate governance practices. For that, it was used the descriptive, bibliographic and survey researches, with qualitative and quantitative approaches. The data collection was performed through a questionnaire, developed with open and closed questions, with simple or multiple choice alternatives, applied in a non-probabilistic sample for accessibility. The study pointed out that the accounting professionals participating in this research perceive that these controls are important in the context of good corporate governance practices, through their principles of transparency, fairness, accountability and corporate responsibility.

Keywords: Corporate Governance. Internal controls. Transparency. Accounting. 


\section{INTRODUÇÃO}

O mercado financeiro mostra-se em constantes transformações, dentre elas as variáveis entre ganhos e perdas econômicas. Um dos fatores para essas mudanças encontra-se na internacionalização dos mercados e seus interesses financeiros em comum. Deste modo, o mercado vem exigindo das empresas maior transparência e confiabilidade nas informações e demonstrações contábeis, bem como uma gestão que reflita credibilidade e competência de seus resultados apresentados. Isso reflete uma busca para diferenciar-se perante o mercado financeiro, com o intuito de apresentar confiança na relação entre empresa e seus stakeholders?'

De tal modo, percebe-se que as boas práticas de governança corporativa se tornaram cada vez mais relevantes para as organizações, seja de grande ou de pequeno porte. O Instituto Brasileiro de Governança Corporativa - IBGC (2009, p.19), define que as boas práticas de governança corporativa "[...] convertem princípios em recomendações objetivas, alinhando interesses com a finalidade de preservar e otimizar o valor da organização, facilitando seu acesso a recursos e contribuindo para sua longevidade".

Desta forma, os gestores de empresas e, em especial, os profissionais do setor de contabilidade necessitam de ferramentas eficazes para aprimorar e acompanhar os sistemas de controles internos, gerando, assim, informações adequadas, confiáveis e que auxiliem os gestores e investidores no processo de tomada de decisão. Neste contexto, questiona-se qual a percepção dos profissionais da área contábil em relação à importância do controle interno no contexto das boas práticas de governança corporativa?

Para resposta ao problema da pesquisa, estabeleceu-se o seguinte objetivo geral: analisar a percepção dos profissionais da área contábil do Vale do Rio dos Sinos/RS em relação à importância do controle interno no contexto das boas práticas de governança corporativa.

O presente estudo justifica-se em compreender a importância do tema tanto para as empresas, quanto para a vida profissional, uma vez que conhecer sobre a governança corporativa, seus benefícios como uma ferramenta de gestão e dos controles internos para demonstrar transparência e confiança nos negócios é um diferencial para uma empresa, bem como credibilidade profissional do setor de contabilidade.

Quanto à metodologia, o presente estudo norteou-se pela pesquisa descritiva, com levantamento (survey) e coleta de dados realizada por meio de um questionário, com perguntas fechadas e abertas com múltiplas escolhas, com opções de simples ou múltipla escolha com a possibilidade de comentários. Os

\footnotetext{
1 "Stakeholders são aqueles que, de outra forma que não acionária, detém importantes interesses na companhia, entre eles, empregados, fornecedores, clientes e a comunidade em geral (SILVA, 2014, p.03)".
} 
questionários foram remetidos aos profissionais da área contábil da região do Vale do Rio dos Sinos/RS, via software Google Drive.

Em relação à estrutura, o artigo divide-se em cinco capítulos. No primeiro capítulo apresentouse a introdução. O capítulo dois, aborda o referencial teórico acerca dos temas governança corporativa, sua importância, controles internos e sua relação com as informações e o sistema contábil. O capítulo três apresenta os procedimentos metodológicos empregados para a realização da pesquisa, no quarto capítulo são analisados os resultados dos dados coletados. Por fim, são apresentadas as considerações finais.

\section{GOVERNANÇA CORPORATIVA E CONTROLE INTERNO}

No contexto histórico a governança corporativa não se trata de um tema dos tempos atuais. Segundo Silva (2014) um trabalho de Berle e Means em 1932 sobre governança, documentou mudanças na composição empresarial norte-americana. Porém a partir dos anos de 1970 intensificou-se o interesse pela abordagem do tema tanto entre os profissionais, quanto entre os acadêmicos.

As discussões sobre o tema governança corporativa tiveram como princípio um tripé firmado pelo Fundo de Investimento LENS², o Relatório Cadbury³ e os Princípios da OCDE (Organization for Economic Cooperation and Development) ${ }^{4}$ (OLIVEIRA, 2006).

Existe grande diversidade institucional e cultural pelo mundo, com isso os modelos de governança corporativa variam entre os países. Embora cada nação pratique modelos diferentes de governança, em geral são divididos em dois sistemas: o anglo-saxão (outsider system - ações são garantidas na bolsa de valores), que prevalece nos Estados Unidos e no Reino Unido, e o nipo-germânico (insider system concentração da propriedade), com o domínio no Japão, na Alemanha e na maioria dos países da Europa continental (SILVA, 2014).

\footnotetext{
${ }^{2}$ Fundo de Investimento LENS: criado nos Estados Unidos pelo ativista Robert Monks em 1992. Através desse fundo originou-se dois valores fundamentais: fairness (senso de justiça) e compliance (conformidade legal, relacionada aos diretos dos investidores minoritários) (ROSSETTI; ANDRADE, 2012).

${ }^{3}$ Relatório Cadbury, foi divulgado em 1992 sendo coordenado por Adrian Cadbury, esse relatório atua na responsabilidades e remuneração dos conselheiros, na relação com os investidores, na prestação de contas, na atribuição dos auditores e conselheiros independentes (OLIVEIRA, 2006).

4 Princípios da OCDE (Organization for Economic Co-operation and Development), em português Organização de Cooperação Econômica de Desenvolvimento, aprovado em 1999. Este princípio compreende a difusão internacional das boas práticas da governança (ROSSETTI; ANDRADE, 2012).
} 
Embora essas considerações sobre governança corporativa já estavam sendo discutido em outros países, no Brasil começaram a ser debatidas apenas no final dos anos 1990. A coordenação pioneira a falar sobre governança, fundada em 1995, foi o Instituto Brasileiro de Conselheiros de Administração (IBCA), hoje com uma nova denominação o Instituto Brasileiro de Governança Corporativa (IBGC) (SILVEIRA, 2010).

Porém, o tema ganhou força a partir de 1998, quando ocorreu vários conflitos entre os controladores e os acionistas minoritários em decorrência de operações de fechamentos de capital de alienação de bloco. Uma vez que os acionistas não controladores se consideravam prejudicados por não possuírem o controle de suas participações acionárias (SILVEIRA, 2010).

A expressão governança corporativa "[...]designa o governo e gestão da empresa, bem como a forma de estrutura societária das sociedades" (RIBEIRO, 2007, p.20). Pode-se observar que existe uma relação entre controle e gestão de uma empresa. A habilidade de administrar diz respeito a capacidade de proporcionar uma boa atuação e desempenho de uma empresa perante ao mercado. Nesse contexto, faz-se necessária uma interação entre as boas práticas da governança corporativa e a estruturação do conselho administrativo, pois esse "[...] é o órgão deliberativo e estruturado com as finalidades básicas de proteger o patrimônio da empresa e de maximizar o retorno dos investimentos dos acionistas" (OLIVEIRA, 2006, p. 4).

Governança corporativa também pode ser compreendida como uma forma de administrar, com o intuito de defender os interesses de uma organização e de seus investidores. Conforme descrito na Cartilha de Governança, (Comissão de Valores Mobiliários - CVM, 2002, p.01) a "Governança corporativa é o conjunto de práticas que tem por finalidade otimizar o desempenho de uma companhia ao proteger todas as partes interessadas, tais como investidores, empregados e credores, facilitando o acesso ao capital".

De acordo com o Instituto Brasileiro de Governança Corporativa (IBGC, 2009, p.19).

Governança Corporativa é o sistema pelo qual as organizações são dirigidas, monitoradas e incentivadas, envolvendo os relacionamentos entre proprietários, Conselho de Administração, Diretoria e órgão de controle. As boas práticas de Governança Corporativa convertem princípios em recomendações objetivas, alinhando interesses com a finalidade de preservar e otimizar o valor da organização, facilitando seu acesso a recursos e contribuindo para sua longevidade.

Assim, as boas práticas da governança corporativa estão vinculadas com melhores decisões tomadas, que estejam em concordância com diferentes interesses da sociedade como um todo (MATIASPEREIRA, 2010). Com isso, as organizações estão mais preocupadas com um gerenciamento voltado ao 
valor do negócio. Com essa nova visão, a administração de uma empresa ganha variáveis importantes para uma gestão diferenciada perante seus concorrentes, bem como a evidenciação de princípios éticos e sociais.

Para Silveira (2010) os mecanismos de governança corporativa precisam estar presentes em qualquer organização lidando com os métodos de decisões entre as principais figuras das instituições, como os administradores, conselheiros, acionistas e executivos, visando que suas decisões valorizem as perspectivas dos seus negócios.

Nesta linha de pensamento, Scherer e Buriol (2011), descrevem que existem buscas por diferentes maneiras de administrar e isso leva a um desafio importante as empresas em demonstrar responsabilidade na gestão, bem como garantir retornos financeiros aos seus investidores e seus acionistas através de atuação de éticas e transparências.

A partir destes conceitos, pode-se afirmar que a governança corporativa favorece a reestruturação de uma organização. No entanto, a sua técnica deve ser adotada de maneira que sua prática traga benefícios estratégicos de gestão que auxilie acionistas, sócios e administradores na tomada de decisão de seus negócios. Com a finalidade de trazer equilíbrio e respeito quanto aos interesses entre mercado e seus objetivos empresariais.

Autores como Rossetti e Andrade (2007) consideram que um bom sistema de governança corporativa auxilia as organizações em suas competências, bem como a se fortalecer para enfrentar novos desafios, a desenvolver estratégias na criação de valores corporativos e, assim, aumentar os resultados, o crescimento econômico, a confiança e o interesse dos investidores.

Esta gestão demonstra comprometimento em gerar riquezas ou benefícios para todos os envolvidos com a empresa. A governança concentra um papel importante de gestão de eficiência, sendo que suas práticas visam reconhecimento de transparência e confiabilidade nos negócios. No Quadro 1, apresentamse os princípios básicos de governança corporativa.

\section{Quadro 1 - Princípios básicos de Governança Corporativa}

\begin{tabular}{|l|l|}
\hline Transparência & $\begin{array}{l}\text { Disponibilização de informações interna e externa de maneira que gere um clima de confiança, } \\
\text { sem restringir o desempenho econômico-financeiro, contudo contemplando demais fatores que } \\
\text { orientam a atuação gerencial e que conduzem à criação de valor. }\end{array}$ \\
\hline Equidade & $\begin{array}{l}\text { Atributo no tratamento justo sem distinção para todos os sócios, acionistas, colaboradores, } \\
\text { clientes, fornecedores, credores, governo, ou seja, partes interessadas (stakeholders). }\end{array}$ \\
\hline Prestação de Contas & $\begin{array}{l}\text { Os agentes de governança precisam prestar contas de sua atuação, assumindo responsabilidade } \\
\text { total de seus atos e omissões. }\end{array}$ \\
\hline $\begin{array}{l}\text { Responsabilidade } \\
\text { Corporativa }\end{array}$ & $\begin{array}{l}\text { os sócios e administradores devem zelar pela sustentabilidade das instituições, tendo em } \\
\text { vista a sua longevidade, atendimento ordem social e ambiental no âmbito dos seus negócios e } \\
\text { operações. }\end{array}$ \\
\hline
\end{tabular}

Fonte: IBGC - Instituto Brasileiro de Governança Corporativa (2009) 
Os benefícios básicos para as empresas são questões estratégicas, como melhorar os modelos de gestão, interação e equidade com diferentes públicos, com isso, ser atrativo "[...] no mercado, a maior segurança na transparência de informações, a melhor atuação ética e social, a estruturação de novos conhecimentos e reestruturação de antigas funções, bem como a efetiva extrapolação das vantagens da governança corporativa para as empresas em geral" (OLIVEIRA, 2006, p. 29).

Pode-se considerar que a Governança Corporativa recomenda aos proprietários, aos administradores, estabelecer boas práticas em gestão estratégica, ética e condutas de confianças considerando a responsabilidade social e ambiental. Sendo assim, a adoção de transparência das informações se faz necessária a qualquer tipo de empresa.

Como questão relevante, consideram-se as organizações que se preocupam em manter relação adequada com seus investidores e acionistas, bem como aumentar o valor dos seus negócios através dos princípios básicos e das boas práticas da governança corporativa, destacando-se diante o mercado financeiro. No entendimento de Ribeiro (2007, p.60) as regras da governança corporativa "[...] visam ampliar os direitos dos acionistas e melhorar a qualidade das informações usualmente prestadas pelas companhias".

Com a adoção da governança corporativa as empresas almejam apresentar confiança perante o mercado e os seus stakeholders, ou seja, proporcionar aos seus investidores resultados que comprovam proteção do patrimônio, interesse e valor da organização, amparado pela transparência de informações, equidade no tratamento igualitário a todos os investidores, excelência na prestação de contas e respeito às leis (OLIVEIRA, 2006).

Em decorrência dessas considerações, percebe-se que as boas práticas da governança corporativa são conduzidas por diversos regulamentos, métodos e códigos que se tornam decisivos para evitar a corrupção, como também prevenir tomadas de decisões errôneas. Esses conceitos compreendem interesses de todos os stakeholders.

Existem diversos conceitos, bem como diferentes definições de governança corporativa como elemento para agregar valores econômicos, gerar benefícios e representar os interesses de todos envolvidos com as instituições. De tal modo, pode-se considerar que ela estabelece importância no processo de gestão, uma vez que suas práticas apresentam transparência nas decisões apresentadas para a sociedade em geral. 


\title{
2.1 GOVERNANÇA CORPORATIVA: INFORMAÇÃO CONTÁBIL
}

O Comitê de Pronunciamentos Contábeis - CPC $00(2008)^{5}$ define que as informações contábil e financeira tornam-se relevantes no momento em que são capazes de fazer a diferença nas decisões tomadas pelos seus usuários. Além disso, a informação pode fazer a diferença em decisões em que os acionistas ou investidores decidirem não achar importante e/ou ter tomado sua ciência por outros meios.

Para Malacrida e Yamamoto (2006, p. 68) existe afinidade entre contabilidade e governança corporativa:

\begin{abstract}
A governança corporativa utiliza os principais conceitos relacionados à Contabilidade, tais com: Transparência (disclosure), equidade, prestação de contas (accountability) e responsabilidade corporativa (sustentabilidade) para explicar e solucionar os conflitos existentes entre os interesses dos stakeholders. Dessa forma, a contabilidade interage com a governança corporativa na tentativa de indicar caminhos, não apenas em relação às questões concernentes aos controles internos como também à prestação de contas, a qual envolve, entre outras, a divulgação das informações a todos interessados (equidade).
\end{abstract}

Diante do exposto, percebe-se que a prestação de contas e a transparência na divulgação das informações contábeis e financeiras estão ligadas às boas práticas da governança corporativa e ao trabalho realizado pela setor de contabilidade. Com essa parceria, tem-se a finalidade de promover ética e integridade perante ao mercado financeiro e a sociedade.

Além disso, pode-se considerar que com a adoção das boas práticas da governança corporativa, os relatórios contábeis tendem a elevar o nível de evidenciação e credibilidade, bem como transparência para seus stakeholders. Visto que as informações devem ser apresentadas a todos os públicos, com o objetivo de alcançar suas necessidades.

Num cenário empresarial globalizado existem diversos interesses e decisões a serem adotadas em conjunto. Por outro lado, existem preocupações com as alterações na legislação, normas e exigências contábeis. E, assim, considera-se importante a análise e os atendimentos de interligações entre os princípios de governança corporativa e as informações publicadas pelo setor de contabilidade. Neste sentido, a seguir evidencia-se a relação das boas práticas de governança corporativa com controles internos auferidas pelo setor de contabilidade.

\footnotetext{
${ }^{5}$ COMITÊ DE PRONUNCIAMENTOS CONTÁBEIS - CPC 00. Estrutura Conceitual para Elaboração e Divulgação de Relatório Contábil-Financeiro.
} 


\subsection{CONTROLES INTERNOS}

O controle interno, conforme as normas da auditoria, consiste em planejar seus processos, implementado e mantido pelos responsáveis da governança, administração, bem como demais colaboradores. Assim, se pode promover segurança razoável para o cumprimento dos objetivos da organização no que se refere à competência dos relatórios financeiros, com concordância das leis e regulamentos em vigor, bem como para a eficiência das operações. A demonstração de "controles" faz referência à alguns aspectos de um ou mais elementos do controle interno (NBC TA 315, 2012)6.

Neste contexto, define-se os objetivos do controle interno: "Obtenção de informação adequada, estimulação do respeito e da obediência às políticas da administração, proteção dos ativos e promoção da eficiência e eficácia operacional" (PEREZ JUNIOR, 2012, p. 79 e 80).

Com base nas normas de auditoria, existem cinco componentes que fornecem uma estrutura que beneficia os aspectos do controle interno de uma empresa. No entanto, esta divisão não reflete como a empresa projeta seus processos de controles internos, podendo-se apresentar e descrever diversos aspectos. Apesar disso, todos os componentes expostos nesta norma são avaliados. Divisão do controle interno em componentes (NBC TA 315, 2012, p. 202):
(a) o ambiente de controle;
(b) o processo de avaliação de risco da entidade;
(c) o sistema de informação, inclusive os processo relacionados de negócios relevantes para os relatórios financeiros e comunicação;
(d) atividades de controle; e
(e) monitoramento de controles.

A atenção nas ferramentas que a organização utiliza para o seu bom funcionamento compreende procedimentos de controle com o intuito de proteger o patrimônio empresarial. Franco e Marra (2007, p. 267) entendem-se como controle interno "[...] todos os instrumentos da organização destinados à vigilância, fiscalização e verificação administrativa, que permitam prever, observar, dirigir ou governar os acontecimentos que se verificam dentro da empresa e que produzam reflexos em seu patrimônio".

Attie (2006, p. 117) define que existem quatro objetivos como regra geral para a gestão do controle interno: "a salvaguarda dos interesses da empresa; a precisão e a confiabilidade dos informes e relatórios contábeis, financeiros e operacionais; o estímulo à eficiência operacional; e a aderência às políticas existentes".

\footnotetext{
${ }^{6}$ NBC TA 315 - NORMAS BRASILEIRAS DE CONTABILIDADE - DE AUDITORIA INDEPENDENTE. Identificação e Avaliação dos Riscos de Distorção Relevante por Meio do Entendimento da Entidade e do seu Ambiente - Definições: Controle Interno.
} 
A prática do controle interno consiste em examinar informações contábeis e dados administrativos, com a finalidade de observar e proteger os bens patrimoniais de uma organização. O AICPA (American Institute of Certified Public Accountants / Instituto Americano dos Contadores Públicos (ertificados) ${ }^{7}$ entende o controle interno como "[...] o plano de organização e todos os métodos e medidas adotadas na empresa para salvaguardar seus ativos, verificar a exatidão e fidelidade dos dados contábeis, desenvolver a eficiência nas operações e estimular o seguimento das políticas administrativas prescritas". (CREPALDI, 2011, p. 376).

De acordo com estes aspectos expostos, pode-se dizer que os controles internos abrangem toda a organização, através de métodos para analisar com exatidão os dados contábeis, com a finalidade governar e tomar decisões, com a intenção de proteger o patrimônio da organização. 0 cumprimento desta área atua em todas as atividades do negócio em que possa ser favorável à administração da organização.

O Comitê de Organizações Patrocinadoras (COSO) ${ }^{\beta}$ fez o primeiro pronunciamento sobre a gestão de controle interno. Assim, entende-se essa administração como "[...] um modelo de metodologia para estruturar e avaliar um sistema de controles internos integrados, com uma postura de identificar, detectar e reagir aos riscos de um negócio, estes com foco nos aspectos financeiros e na finalidade de transparência e adequação das demonstrações contábeis". (COSO, 2007, apud MACHADO, 2011, p. 14).

A composição do comitê O COSO obteve abrangência com foco contábil e de gestão do controle interno com o intuito de se impedir a fraude empresarial. Assim, dois pronunciamentos surgiram, o cOSO Report ou COSO I, com o desígnio no controle interno contábil. E o COSO ERM ou COSO II, com a finalidade de ampliar a gestão das entidades, em específico sobre o que se refere aos riscos. Com isso, considerase ampla a gestão de risco corporativo, sendo esse de origem tanto interna, quanto externa. O elemento risco refere-se a um controle interno, ou seja, com a possibilidade de ocorrência de riscos resultam os modelos de gestão de risco. Devido a essas circunstâncias, os mercados de capitais e financeiros mundiais passaram a se importar com tudo o que se relaciona aos riscos, sobretudo no que se refere a fraudes, à lavagem de dinheiro e riscos sistêmicos (MACHADO, 2011).

A interpretação bem como a importância do controle interno abrange o conjunto de metodologia e de prática com referência à ação de controlar riquezas contra quaisquer riscos de irregularidades, isto é, o controle interno tem por finalidade evitar casos de fraudes e gestão inadequada.

\footnotetext{
7 AICPA (Institute of Certified Public Accountants) - A maior associação de membros do mundo representando a profissão de contadores. Estabelece padrões éticos para a profissão e padrões de auditoria dos EUA para organizações privadas, sem fins lucrativos, governos federal, estaduais e locais (AICPA,2017).

${ }^{8} \mathrm{O}$ COSO (The Committee of Sponsoring Organizations) - é uma entidade sem fins lucrativos, dedicada à melhoria dos relatórios financeiros através da ética, efetividade dos controles internos e governança corporativa (PORTAL DE AUDITORIA, 2016).
} 


\begin{abstract}
Em alguns casos, a ocorrência de fraudes pode ser evitada se for empregada uma boa estrutura de controle interno. A postura administrativa parece ser o fator determinante para a existência de fraudes e criação de um contexto empresarial tolerante com atos complacentes (vista grossa) e de descontrole (PEREIRA, 2009, p. 112).
\end{abstract}

A partir desses conceitos e definições compreende-se que o controle interno exerce um papel importante no que se refere a verificação de métodos, coordenação e constatação dos cumprimentos de normas legais, bem como a execução das regras operacionais administrativas de uma empresa, como também uma supervisão geral pelo controle de erros e ou fraudes, com o intuito de se proteger o desempenho e o patrimônio de uma entidade.

\title{
2.3 CONTROLE INTERNO E O SISTEMA CONTÁBIL
}

Um dos instrumentos principais para os procedimentos do controle interno se deve ao setor de contabilidade. Em outras palavras, através da realização do trabalho contábil obtém-se os resultados patrimoniais de uma instituição, por meio da escrituração e registro dos fatos após as ocorrências administrativas.

Percebe-se a importância do controle interno no momento em que se verifica a sua eficiência em garantir a continuidade do fluxo operacional interno de uma instituiç̧ão. Assim, pode-se entender que a contabilidade agrega valor fundamental para os empresários e aos usuários que utilizam-se dos seus resultados para tomada de decisões. Com isso, entende-se que as empresas possuem, de uma forma ou outra, algum tipo de controle interno, embora em algumas o controle não seja efetivo como deve ser (CREPALDI, 2011).

Avaliações adequadas no controle interno podem refletir ou não naapresentação dos saldos contábeis de uma instituição. Este ponto se torna relevante como baseamento, bem como para a determinação do grau de confiança nos procedimentos aplicados no controle interno de uma empresa. Devem ser feitos estudos que avaliem o "[...] sistema de controle interno das operações para assegurar que os documentos e informações processadas pela contabilidade são decorrentes de operações fidedignas e realizadas em função dos objetivos das empresas". (PEREZ JUNIOR, 2012, p. 79).

A finalidade do controle interno é averiguar o sistema de contabilidade como um todo, ou seja, verificar todos os documentos e o registro das notas fiscais, boletos, guias, faturas, livros entre outros dados. A averiguação desses elementos ocorre com a relação entre a precisão e a confiabilidade dos relatórios contábeis e financeiros apresentadas, sejam adequadas ou não.

Os principais meios que podem ser utilizados para o apoio necessário no que se refere à precisão e confiabilidade das informações apresentadas nos relatórios contábeis e financeiros. São eles: Documentos 
Confiáveis: utilização de documentos aptos para o registro das ocorrências; Conciliação: indicação de precisão ou divergências existentes nas informações, e eliminação de pendências; Análise: identificação dos itens em exame, de modo que permite a constatação de sua composição; Plano de Contas: classificação adequada de cada conta, com a classificação dos dados da empresa; Tempo Hábil: registro das transações obedecendo o período de competência; Equipamento Mecânico: utilização de equipamentos mecânicos ou eletrônicos, tendo em vista agilizar o registro das transações (ATTIE, 2006).

Para se entender melhor a relação entre controle interno e o controle contábil, Perez Junior (2012) apresenta uma classificação dos controles internos, sendo esses divididos em dois grupos. Primeiramente, os controles administrativos - um controle a respeito das operações da organização e a qualidade dos elementos e documentos a serem contabilizados. No segundo grupo, os controles contábeis - apresentar segurança e qualidade dos registros contábeis e demonstrações contábeis, em outras palavras, proteger os ativos da empresa.

Neste contexto, entende-se que avaliações apropriadas de controle interno de uma empresa propiciam uma comunicação favorável no que se refere às apresentações das demonstrações contábeis. Com um bom desempenho entre o conjunto das transações executadas e os procedimentos de controles, permite-se aumentar os aspectos de confiança, como também diminuir a pré-disposição de erros e ou fraudes.

Os métodos e procedimentos, definidos para a coleta e análise dos dados do presente artigo, são apresentados na próxima seção.

\section{PROCEDIMENTOS METODOLÓGICOS}

Neste estudo foi empregada a pesquisa descritiva, que tem o objetivo descrever as propriedades de uma população determinada (GIL, 2010). A abordagem empregada foi predominantemente quantitativa por meio de um levantamento (survey), em uma população definida de forma intencional, por conveniência, em consonância com o objetivo do estudo. Busca-se conhecer a percepção dos contadores em relação à importância do controle interno no contexto das boas práticas de governança corporativa

O universo da pesquisa foi composto pelos profissionais contábeis vinculados a Associação dos Contabilistas do Vale do Rio do Sinos, objeto do presente estudo. Assim, do universo de 75 respondentes, a pesquisa obteve a resposta de 22 profissionais.

Como instrumento de coleta de dados, definiu-se o questionário, que é o instrumento mais usado para esse tipo de pesquisa (BEUREN, 2006) e encontra-se disponível no Apêndice A. Ele foi elaborado com base nas características identificadas por meio da revisão da literatura e adaptados ao contexto da 


\section{Gestãoe \\ Desenvolvimento}

e-ISSN: 2446-6875

p-ISSN: $1807-5436$

pesquisa. O presente questionário foi composto de 11 questões com perguntas do tipo abertas e fechadas, com opções de simples ou múltiplas escolhas, com a possibilidade de comentários, visando, deste modo, alcançar os objetivos deste estudo. As questões foram organizadas em blocos, o primeiro tratou do perfil dos respondentes apresentados no Quadro 2.

\section{Quadro 2 - Perfil dos Respondentes}

\begin{tabular}{|c|c|c|c|}
\hline Respondente & Idade & Sexo & Formação \\
\hline R1 & 36 a 45 anos & Feminino & MBA/Pós-Graduação \\
\hline $\mathrm{R} 2$ & 26 a 35 anos & Masculino & MBA/Pós-Graduação \\
\hline R3 & 26 a 35 anos & Feminino & Nível Superior (Ciências Contábeis) \\
\hline R4 & 26 a 35 anos & Masculino & MBA/Pós-Graduação \\
\hline R5 & 26 a 35 anos & Feminino & MBA/Pós-Graduação \\
\hline R6 & 26 a 35 anos & Feminino & Nivel Superior (Ciências Contábeis) \\
\hline R7 & 26 a 35 anos & Feminino & Nivel Técnico (Contabilidade) \\
\hline R8 & 26 a 35 anos & Feminino & MBA/Pós-Graduação \\
\hline R9 & 26 a 35 anos & Masculino & MBA/Pós-Graduação \\
\hline R10 & 26 a 35 anos & Masculino & Nível Superior (Ciências Contábeis) \\
\hline $\mathrm{R} 11$ & 46 a 55 anos & Masculino & Nivel Superior (Ciências Contábeis) \\
\hline R12 & 26 a 35 anos & Feminino & MBA/Pós-Graduação \\
\hline R13 & 46 a 55 anos & Masculino & MBA/Pós-Graduação \\
\hline R14 & Até 25 anos & Masculino & Nivel Superior (Ciências Contábeis) \\
\hline R15 & 56 anos ou mais & Feminino & MBA/Pós-Graduação \\
\hline R16 & 26 a 35 anos & Masculino & Nivel Superior (Ciências Contábeis) \\
\hline R17 & 46 a 55 anos & Masculino & Nivel Superior (Ciências Contábeis) \\
\hline $\mathrm{R} 18$ & 56 anos ou mais & Feminino & Nivel Técnico (Contabilidade) \\
\hline R19 & 46 a 55 anos & Masculino & Nivel Superior (Ciências Contábeis) \\
\hline R20 & 36 a 45 anos & Masculino & Nível Técnico (Contabilidade) \\
\hline R21 & 56 anos ou mais & Masculino & Nivel Técnico (Contabilidade) \\
\hline $\mathrm{R} 22$ & 46 a 55 anos & Masculino & Nivel Superior (Ciências Contábeis) \\
\hline
\end{tabular}

\section{Fonte: Dados da Pesquisa}

O segundo abordou os conceitos de Governança Corporativa; o terceiro tratou dos conceitos de Controle Interno e o quarto abrangeu a importância e as contribuições da governança corporativa e do controle interno. Os blocos foram organizados desta forma com o intuito de responder o objetivo definido.

A coleta de dados ocorreu no mês de abril de 2017, via correio eletrônico onde foi disponibilizado o link desenvolvido com o auxílio do software Google Drive e ficou à disposição dos respondentes de forma on-line por um período de quinze dias. Para a análise dos resultados, as respostas recebidas foram 
tabulados em uma planilha eletrônica e na sequência foi realizada a interpretação dos resultados com a finalidade de promover as interpretações de maneira que conserve a personalidade das respostas. Na próxima seção, são apresentados os resultados obtidos a partir da coleta de dados realizada.

\section{ANÁLISE DE DADOS}

Neste capítulo demonstra-se a análise de dados dos elementos referente à pesquisa com os profissionais da área contábil. O subcapítulo a seguir apresenta respostas do bloco l, cujo enfoque recai na identificação dos respondentes. Assim, pode-se ter conhecimento do perfil dos participantes da pesquisa.

\subsection{BLOCO I - IDENTIFICAÇÃO DOS RESPONDENTES}

As respostas recebidas acerca da identificação dos respondentes evidenciaram que todos os respondentes são profissionais da área contábil, ou seja, contadores do Vale do Rio dos Sinos/RS. Dos vinte e dois (22) profissionais respondentes, nove (09) são do sexo feminino e treze (13) do sexo masculino. nove (09) tem a formação em MBA/Pós-graduação. A área de atuação predominante é a contabilidade geral, representada por treze (13) respondentes. Quanto à variável do tempo de experiência na função, oito (08) mencionaram que possuem até 5 anos de experiência enquanto seis (06) indicaram atuara há 21 anos ou mais. A constituição legal da maioria das empresa em que os respondentes atuam é a LTDA (limitada), com dezessete (17) das respostas. Quanto à sede da empresa dezoito (18) dos respondentes pertencem à cidade de Novo Hamburgo/RS. A seguir, apresenta-se os resultados do bloco ll cujo propósito foi o de abordar os conceitos de governança corporativa.

\subsection{BLOCO II - CONCEITOS DE GOVERNANÇA CORPORATIVA}

Na primeira questão do bloco II, perguntou-se aos respondentes: Qual dos conceitos melhor se enquadra no seu entendimento sobre governança corporativa? Analisando as respostas, verificou-se que a maioria dos profissionais entendem que a governança corporativa é um conjunto de métodos e técnicas com a finalidade de otimizar a atuação de uma organização, bem como de proteção de todos os stakeholders. 


\section{Gestãoe \\ Desenvolvimento}

e-ISSN: 2446-6875

p-ISSN: $1807-5436$

No Gráfico 1, apresenta-se os resultados das respostas recebidas para a primeira questão.

Gráfico 1 - Conceitos de Governança Corporativa

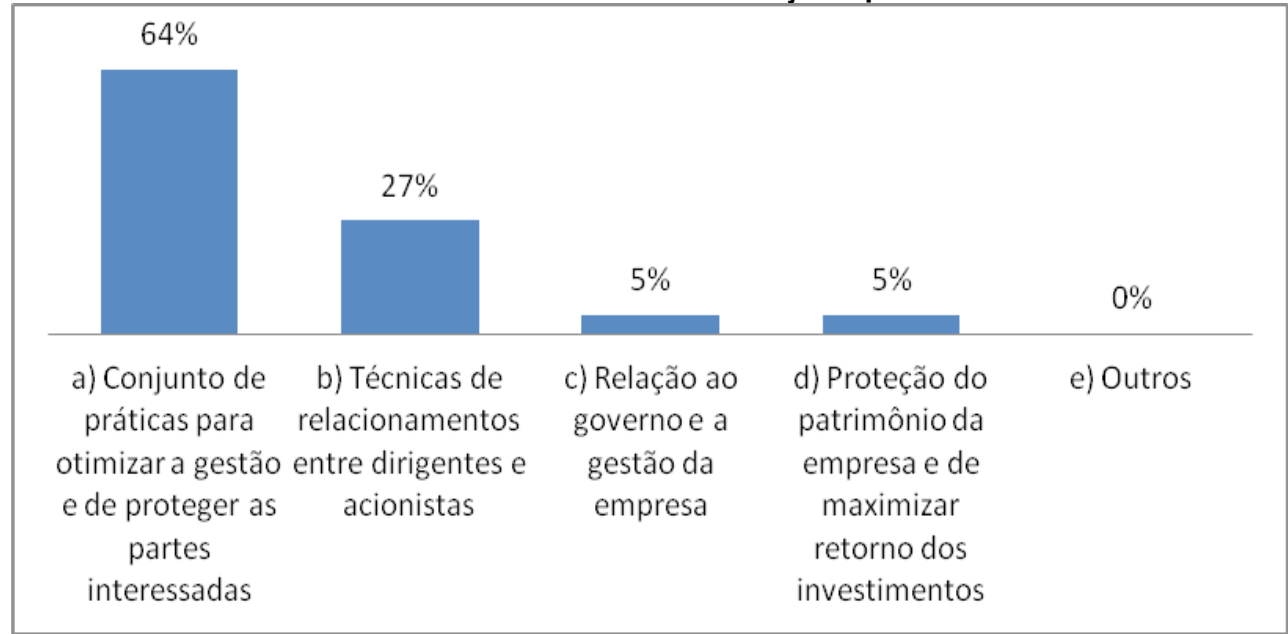

\section{Fonte: Dados da Pesquisa}

No Gráfico 1, observou-se que sessenta e quatro por cento (64\%) dos respondentes assinalaram a opção na qual a governança corporativa é compreendida como um conjunto de práticas para otimizar a gestão e proteger as partes interessadas. Sendo que vinte sete por cento $(27 \%)$ dos profissionais escolheram o conceito que se refere às técnicas de relacionamentos entre dirigentes e acionistas.

Na questão dois (02), perguntou-se aos profissionais, quais os princípios da governança corporativa consideravam fundamentais para a organização? Vinte (20) dos profissionais assinalaram que o princípio mais relevante é o da transparência. Doze (12) dos respondentes entendem que o princípio fundamental para a empresa é o da responsabilidade corporativa. Já dez (10) escolheram a opção equidade, e nove (09) indicaram a alternativa a prestação de contas.

Em complemento da questão dois (02), o Quadro 3 apresenta as respostas recebidas para a pergunta três (03), que questionou quais os motivos das empresas adotarem a governança corporativa considerando os princípios da transparência, equidade, prestação de contas e responsabilidade corporativa, na percepção do respondente. 


\section{Gestãoe \\ Desenvolvimento}

e-ISSN: 2446-6875

p-ISSN: 1807-5436

Quadro 3 - Motivos Adoção Governança Corporativa considerando seus princípios

\begin{tabular}{|c|c|}
\hline Respondente & Respostas \\
\hline R1 & No meu ponto de vista, a principal razão é visando a longevidade da entidade. \\
\hline $\mathrm{R} 2$ & Melhoria nos processos e ganho de rendimento em todos setores. \\
\hline R3 & $\begin{array}{l}\text { As práticas de Governança visam superar as divergências entre sócio e administrador visando a } \\
\text { equalizar as questões administrativas da empresa, com ferramentas de monitoria alinhando o } \\
\text { comportamento do todo pelo bem da empresa. }\end{array}$ \\
\hline R4 & Melhorar a eficiência e eficácia, buscando sempre a maximização dos resultados. \\
\hline R5 & $\begin{array}{l}\text { As empresas acabam adotando a governança corporativa para passar um alto grau de confiança aos } \\
\text { interessados, como, investidores, clientes, fornecedores, bancos e também em relação aos controles } \\
\text { internos da empresa, para que a mesma seja melhor administrada. }\end{array}$ \\
\hline R6 & Para que todos possam zelar pela viabilidade econômica da organização. \\
\hline R7 & Os princípios são uma forma de alinhar os interesses de todas a partes. \\
\hline R8 & $\begin{array}{l}\text { Acredito que para gerarem maior credibilidade perante aos investidores, agregando valor para a } \\
\text { empresa, além é claro, de tentar reduzir os casos de fraudes e roubos internos. }\end{array}$ \\
\hline R9 & Otimizar e dar maior credibilidade à gestão. \\
\hline $\mathrm{R} 10$ & Prevenção contra fraudes e análise de desempenho \\
\hline R11 & Valorização da sua imagem no mercado. \\
\hline & Melhor percepção pelo mercado. Adicionar valor à empresa. \\
\hline R13 & $\begin{array}{l}\text { Para que haja transparência entre os executivos e os investidores e/ou sócios da organização; para } \\
\text { que a organização esteja em "compliance" tanto perante o governo como perante à gestão interna e } \\
\text { investidores/sócios }\end{array}$ \\
\hline R14 & $\begin{array}{l}\text { Para que haja menos distância entre os gestores e os funcionários. } \\
\text { O governo das sociedades, na era digital, exige cuidados extremos em relação ao conjunto de suas } \\
\text { práticas administrativas e de controle na preservação de sua imagem no mercado, o que requer a } \\
\text { adesão de todas as partes envolvidas, em especial gestores, acionistas, e funcionários. } \\
\text { Para o alcance de tal propósito é imprescindivel implantar um conjunto de normas e procedimentos } \\
\text { comuns a todos os envolvidos, que através da colaboração de cada qual leva ao alcance do resultado } \\
\text { e objetivos definidos. A teoria é muito interessante, mas na prática as situações de conflito persistem } \\
\text { e a transparência sempre acaba prejudicada. }\end{array}$ \\
\hline R16 & $\begin{array}{l}\text { Buscar aumentar a eficiência e segurança nas operações da empresa e proporcionar maior } \\
\text { confiabilidade perante seus stakeholders. }\end{array}$ \\
\hline R17 & $\begin{array}{l}\text { Motivos acima são os básicos para a empresa aprimorar seus processos, estes de interesse próprio e } \\
\text { visando também possibilidades futuras de negociações com investidores. Estes certamente verão a } \\
\text { empresa positivamente. }\end{array}$ \\
\hline R18 & Melhor controle \\
\hline R19 & Segurança nas informações \\
\hline R20 & O controle do fisco sobre as empresas e as constantes mudanças de mercado. \\
\hline $\mathrm{R} 21$ & Resposta à sociedade \\
\hline $\mathrm{R} 22$ & Capacitar a empresa de tal forma que a torne organizada, controlada e rentável. \\
\hline
\end{tabular}

\section{Fonte: Dados da Pesquisa}




\section{Gestãoe \\ Desenvolvimento}

e-ISSN: 2446-6875

p-ISSN: $1807-5436$

Um dos pontos relevantes para a prática de governança corporativa são seus princípios, ou seja, a transparência, a equidade, a prestação de contas e a responsabilidade corporativa. Assim, com base nas respostas apresentadas, a maioria dos profissionais entendem que esses princípios exercem um papel e uma ação importante na gestão da instituição, sendo que suas práticas apontam para a consideração de transparência e confiabilidade nos mercados.

Na sequência da análise do estudo, apresenta-se o bloco III, que demonstra os conceitos do controle interno.

\subsection{BLOCO III - CONCEITOS DE CONTROLE INTERNO}

Neste bloco, a pergunta um (01), questiona qual dos conceitos se entende como o mais importante para definir o controle interno, na percepção dos profissionais da área contábil. Nesta questão aceita-se somente uma resposta. Segue o Gráfico dois (02) com as respostas obtidas.

Gráfico 2 - Conceitos de Controle Interno

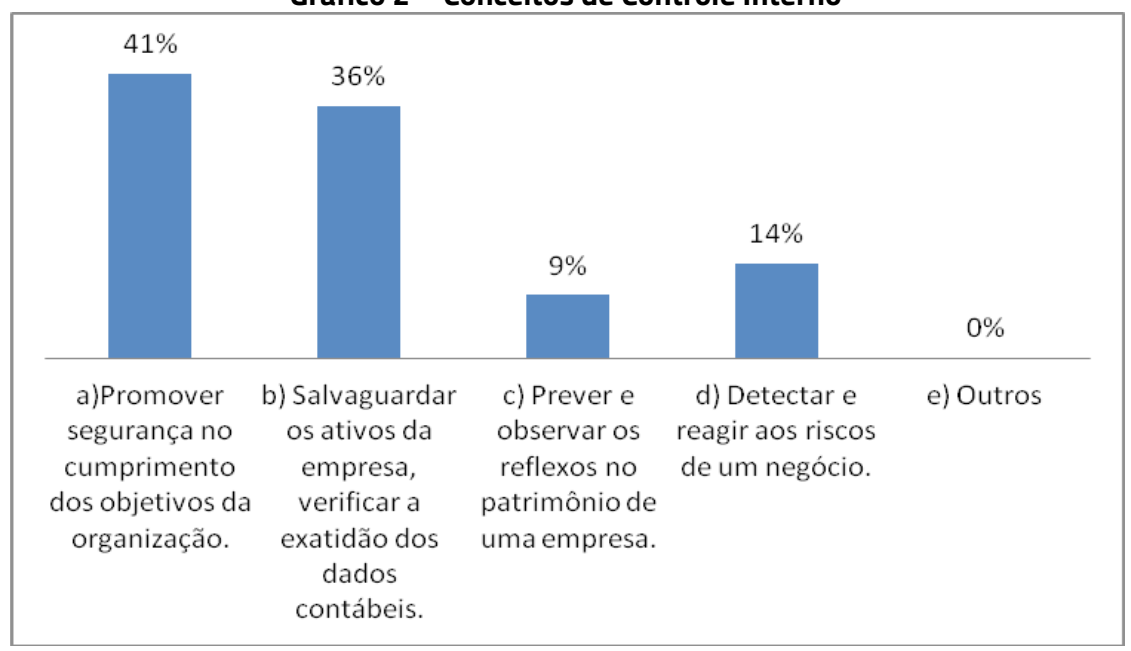

Fonte: Dados da Pesquisa

Observou-se que quarenta e um por cento (41\%) dos respondentes entendem que a importância do controle interno está em promover a segurança para o realização dos objetivos da organização. Já trinta e seis por cento $(36 \%)$ percebem que esse controle serve para salvaguardar os ativos da empresa, bem como averiguar a exatidão dos dados contábeis.

As normas da auditoria indicam planejar métodos, praticados e mantidos por seus responsáveis da governança, em promover segurança razoável para o cumprimento dos objetivos da organização no que se refere à competência dos relatórios financeiros, em concordância com as leis e regulamentos em vigor. 


\section{Gestãoe \\ Desenvolvimento}

e-ISSN: 2446-6875

p-ISSN: $1807-5436$

A demonstração de controles refere-se a alguns aspectos de um ou mais elementos do controle interno (NBC TA 315, 2012).

A prática do controle interno consiste em examinar informações contábeis e dados administrativos, com a finalidade de observar e proteger os bens patrimoniais de uma organização. Assim, nota-se que os profissionais contábeis pesquisados compreendem essa relação com a literatura, bem como percebem a importância do controle interno exercido nas empresas.

A questão dois (02) desse bloco, fez menção ao O COSO, como ampliação da gestão de riscos corporativos. Desta forma, solicitou aos respondentes, se concordavam ou não que sua aplicação apresenta provável segurança nas divulgações dos resultados das organizações. As respostas constam no Gráfico três (03).

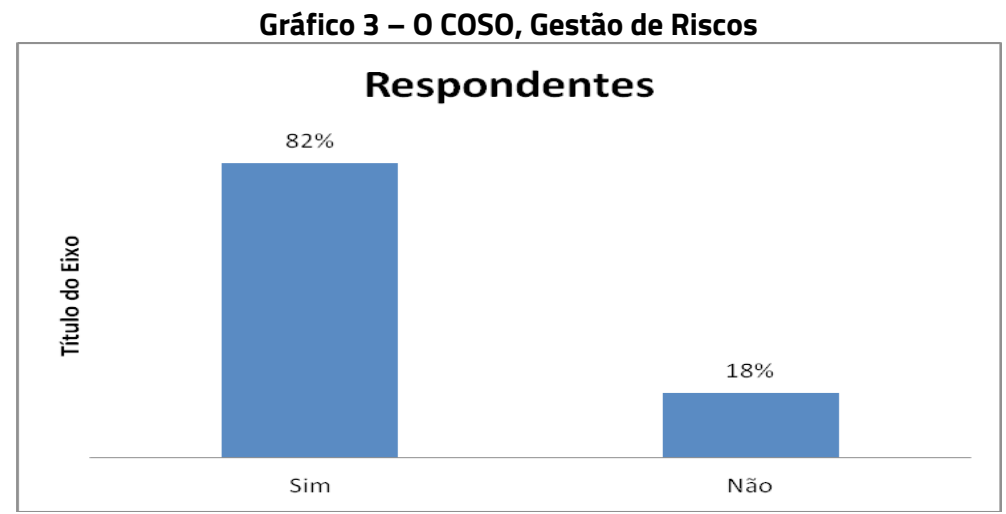

Fonte: Dados da Pesquisa

Ressalta-se que oitenta e dois por cento (82\%) dos participantes da pesquisa entendem que a aplicabilidade de O COSO, apresenta razoável segurança em prevenir fraudes empresariais, bem como em suas divulgações contábeis. No Quadro 4 são mencionados comentários de alguns respondentes. 


\section{Quadro 4 - 0 cOSO, Gestão de Riscos}

\begin{tabular}{|l|l|}
\hline \multicolumn{1}{|c|}{ Respondente } & \multicolumn{1}{c|}{ Comentários } \\
\hline R1 & $\begin{array}{l}\text { Na minha opinião, toda empresa que aplica métodos de padronização com as normas, apresentará um a } \\
\text { contabilidade mais segura, logo, divulgará as mesmas de maneira mais transparente e adequada. }\end{array}$ \\
\hline R3 & $\begin{array}{l}\text { A segurança existe desde que as partes envolvidas façam uso de forma correta dos controles internos } \\
\text { seguindo a legislação contábil. }\end{array}$ \\
\hline R12 & $\begin{array}{l}\text { Se os controles são efetivos e monitorados, representam maior segurança para a empresa, com } \\
\text { probabilidade maior de detecção de fraudes e riscos de negócio. }\end{array}$ \\
\hline R13 & $\begin{array}{l}\text { O controle interno é fundamental para a organização, é a ferramenta que sustenta a governança } \\
\text { corporativa, detectando riscos e avaliando metas/desempenhos. }\end{array}$ \\
\hline R15 & $\begin{array}{l}\text { Fraudes são planejadas de modo a passarem despercebidas aos controles internos, e, em geral, são } \\
\text { identificadas porque os envolvidos, com a rotina, acabam de descuidando dos fatores de segurança } \\
\text { envolvidos, como, por exemplo, sinais exteriores de riqueza. }\end{array}$ \\
\hline R16 & $\begin{array}{l}\text { Penso que quando há qualquer processo/controle com intuito de prevenir ações negativas dentro de } \\
\text { uma organização, esta tende a se comportar em conformidade com as normas e legislações vigentes. } \\
\text { Assim, para estas empresas, em comparação com outras que não adotam nenhuma forma de controle } \\
\text { interno, creio que haverá maior segurança e credibilidade em suas divulgações de resultados. }\end{array}$ \\
\hline R17 & $\begin{array}{l}\text { Resultados contábeis serão fidedignos se a empresa adota rigoroso controle interno, prevendo falhas } \\
\text { intencionais ou não, sendo menos oneroso para a empresa o custo dos controles preventivos. }\end{array}$ \\
\hline R22 & Traz mais exatidão e credibilidade às informações. \\
\hline
\end{tabular}

\section{Fonte: Dados da Pesquisa}

O coso proporciona foco contábil e de gestão do controle interno com a finalidade de se prevenir a fraude institucional. 0 componente risco refere-se a um controle, tanto interno, quanto externo, e essas ocorrências derivam de modelos de gestão de risco. Com relação às respostas, bem como aos comentários, pode-se perceber que na percepção dos respondentes esse modelo de controle interno tem intuito de detectar e reagir a possíveis riscos e fraudes, com a finalidade de demonstrar relatórios financeiros e demonstrações contábeis adequados.

Na questão três (03) solicitou-se aos profissionais da área contábil, qual dos cinco componentes básicos citados pela NBC TA 315 consideram mais importantes. Nesta questão foi possível assinalar mais de uma opção.

Quadro 5 - Componentes NBC TA 315

\begin{tabular}{|l|l|}
\hline \multicolumn{1}{|c|}{ Componentes NBC TA 315} & \multicolumn{1}{c|}{ Respondentes } \\
\hline a) O ambiente de controle & $R 12, R 20$ \\
\hline b) O processo de avaliação de riscos da entidade & $R 3, R 5, R 6, R 10, R 12, R 14, R 18, R 19$ \\
\hline c) O sistema de informação & $R 3, R 5, R 7, R 8, R 9, R 12, R 13, R 20, R 22$ \\
\hline d) Atividades de controle & $R$ 9, R10, R12, R13 \\
\hline e) Monitoramento de controle & $R 3, R 4, R 5, R 9, R 11, R 12$ \\
\hline f) Outros & $R 1, R 2, R 15, R 16, R 21$ \\
\hline
\end{tabular}




\section{Gestãoe \\ Desenvolvimento}

e-ISSN: 2446-6875

p-ISSN: $1807-5436$

De acordo as respostas obtidas, observa-se que a opção "c" foi selecionada por nove (09) dos respondentes, já oito (08) definiram que a opção "b" é a mais importante em suas concepções. As demais opções foram selecionadas, porém com menor intensidade. É importante ressaltar, que cinco (05) dos profissionais expressaram que não tem conhecimento sobre essa norma. O Quadro 6 apresenta os comentários desses cinco (05) respondentes.

Quadro 6 - Componentes NBC TA 315

\begin{tabular}{|l|l|}
\hline \multicolumn{1}{|c|}{ Respondentes } & \multicolumn{1}{c|}{ Opção “Outros” } \\
\hline R1 & $\begin{array}{l}\text { Nossa empresa ainda é muito pequena, e não estamos tão bem estruturados. Não temos como } \\
\text { responder a essa pergunta de maneira adequada. Por enquanto, somos sobreviventes e bombeiros. }\end{array}$ \\
\hline R2 & Desconheço. \\
\hline R15 & Fazemos a verificação desses componentes nas empresas através da assessoria. \\
\hline R16 & Em sua essência, a empresa não aplica nenhum destes controles. \\
\hline R21 & Empresa não aplica \\
\hline
\end{tabular}

Fonte: Dados da Pesquisa

Esses componentes fornecem uma estrutura que beneficia os aspectos do controle interno de uma empresa, no entanto esta divisão não reflete essencialmente como a empresa projeta seus processos de controle interno, podendo apresentá-los e descrevê-los de diversas maneiras (NBC TA 315, 2012).

Mesmo que alguns dos respondentes não conheçam esses aspectos de controle, a maioria dos profissionais, dezessete (17), compreendem que o controle interno apresenta significado e importância, possuindo a função de observar e avaliar os processos tanto administrativos, quanto gerenciais. Deste modo, o controle interno demonstra-se como um elemento que analisa e pondera uma atividade, bem como relatórios financeiros e contábeis.

\subsection{BLOCO IV - IMPORTÂNCIA E CONTRIBUIÇÕES DA GOVERNANÇA CORPORATIVA E DO CONTROLE INTERNO}

Na questão sete solicitou-se que os profissionais participantes da pesquisa identificassem em suas opiniões, quais das boas práticas de governança corporativa elencadas entendiam como a mais importante. 


\section{Gestãoe \\ Desenvolvimento}

e-ISSN: 2446-6875

p-ISSN: $1807-5436$

Gráfico 4 - Boas Práticas de Governança Corporativa

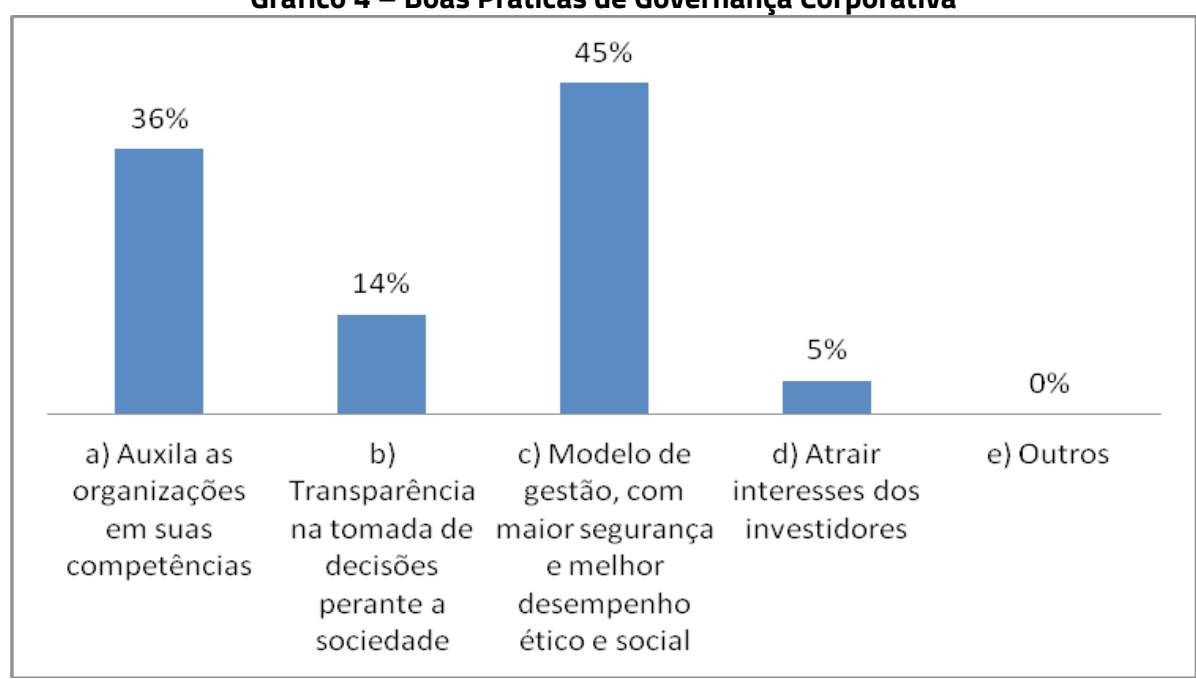

Fonte: Dados da Pesquisa

Considerando as alternativas propostas, a maioria dos respondentes marcaram a opção "c" e "a" como as mais importantes no que se refere às boas práticas de governança.

Essas boas práticas podem trazer um modelo de gestão, interação e equidade para diferentes públicos, bem como ser atrativo no mercado, comprovar transparência de informações, atuação ética e social, trazer conhecimentos e reestruturação de antigas funções, e benefícios da governança corporativa para as empresas em geral (OLIVEIRA, 2006).

Um sistema de governança corporativa adequado possui o intuito de proteger as instituições em suas competências, como também auxiliar a enfrentar novos desafios, a ampliar estratégias e assim aumentar os resultados, a confiança e interesse dos investidores (ROSSETTI; ANDRADE, 2007).

Como enfoque da pesquisa, observa-se que os respondentes entendem que as boas práticas são importantes para a governança corporativa, pois essas técnicas trazem competências, transparências para a tomada de decisões, bem como tornam-se atrativos para os investidores, trazendo valor, bem como ética para a instituição.

Na pergunta oito (08) questionou-se. Quais são as contribuições da governança corporativa no processo e na divulgação das informações contábeis? E, na questão nove (09) questionou-se Quais as contribuições do controle interno para a confiabilidade nas informações contábeis? Em ambas as questões permitiu-se a escolha de mais de uma resposta. 
Quadro 7 - Contribuições da Governança Corporativa e do Controle Interno - Informações Contábeis

\begin{tabular}{|l|l|}
\hline \multicolumn{1}{|c|}{ Contribuições da Governança Corporativa - Informações Contábeis } & \multicolumn{1}{|c|}{ Respondentes } \\
\hline a) Informações relevantes e precisas & $R 2, R 3, R 4, R 5, R 9, R 12, R 13$ \\
\hline $\begin{array}{l}\text { b) Auxilia administradores e investidores na tomada de decisões dentro } \\
\text { e fora da organização }\end{array}$ & $R 2, R 3, R 5, R 6, R 8, R 9, R 14, R 16, R 20, R 22$ \\
\hline $\begin{array}{l}\text { c) Prestação de contas e transparência nas divulgações das informações } \\
\text { contábeis }\end{array}$ & $R 3, R 8, R 9, R 13, R 14, R 16, R 17, R 18, R 19$ \\
\hline d) Evidenciar valores para a marca da organização & $R 9, R 12, R 15$ \\
\hline e) Suprir os interesses dos administradores, investidores e acionistas & $\begin{array}{l}\text { R1, R2, R3, R4, R5, R7, R9, R10, R11, R16, R17, } \\
R 21, R 22\end{array}$ \\
\hline f) Outros & \\
\hline \multicolumn{1}{|c|}{ Contribuições do Controle Interno - Informações Contábeis } & \multicolumn{1}{c}{ Respondentes } \\
\hline $\begin{array}{l}\text { a) Proteção patrimonial da empresa e confiabilidade nas demonstrações } \\
\text { contábeis }\end{array}$ & $\begin{array}{l}R 2, R 3, R 4, R 5, R 11, R 13, R 15, R 16, R 17, R 18, \\
R 19, R 20\end{array}$ \\
\hline $\begin{array}{l}\text { b) Confiabilidade sobre as informações apresentadas nos relatórios } \\
\text { contábeis e financeiros }\end{array}$ & $R 1, R 2, R 3, R 5, R 6, R 7, R 8, R 9, R 10, R 12, R 13$, \\
\hline $\begin{array}{l}\text { c) Confiança dos resultados apresentados como base para tomada de } \\
\text { decisões }\end{array}$ & $\begin{array}{l}R 1, R 3, R 22 \\
R 18, R 21\end{array}$ \\
\hline $\begin{array}{l}\text { d) Certificação dos documentos e informações processadas pela } \\
\text { contabilidade }\end{array}$ & $R 14, R 17, R 18, R 22$ \\
\hline e) Qualidade dos registros contábeis e demonstrações contábeis & $R 1, R 9, R 12, R 16, R 18$ \\
\hline f) Outros & \\
\hline
\end{tabular}

\section{Fonte: Dados da Pesquisa}

Nestas duas questões, os profissionais assinalaram quase todos os itens, demonstrando assim que as contribuições indicadas, tanto da governança, quanto do controle interno, trazem confiabilidade para as informações contábeis. No que se refere à contribuição da governança corporativa para as informações contábeis, a alternativa "e" foi apontada por treze (13) dos profissionais. Já o que faz menção ao controle interno como contribuição às informações contábeis, quatorze (14) respondentes optaram pela opção "b".

Com o que foi observado, na opinião dos respondentes, pode-se entender que a governança corporativa e o controle interno contribuem para, de uma forma ou de outra, trazer confiabilidade, bem como relevância para as informações contábeis através de transparência, equidade, prestação de contas, responsabilidade corporativa. Assim, a contabilidade relaciona-se com a governança corporativa bem como indica afinidade com aos controles internos, ou seja, interação entre prestação de contas e a divulgação das informações a todos interessados.

Na questão quatro (04), perguntou-se aos profissionais, qual a percepção, quanto aos aspectos dos controles internos, que exercem importância para a boas práticas da governança corporativa. Nessa pergunta o foco foi a alternativa mais importante. 


\section{Gestãoe \\ Desenvolvimento}

e-ISSN: 2446-6875

p-ISSN: $1807-5436$

Quadro 8 - Controle Interno importância para as práticas da Governança Corporativa

\begin{tabular}{|c|c|}
\hline $\begin{array}{c}\text { Controle Interno importância para as práticas da } \\
\text { Governança Corporativa }\end{array}$ & Respondentes \\
\hline $\begin{array}{l}\text { a)Respeito e obediência às políticas da administração da } \\
\text { empresa }\end{array}$ & R1 ,R2, R3, R7, R12, R13, R14, R15, R16, R18 \\
\hline b) Evitar casos de fraudes e gestão inadequada & $\begin{array}{l}R 1, R 2, R 3, R 4, R 5, R 8, R 9, R 10, R 11, R 13, R 14, R 17, R 21 \text {, } \\
R 22\end{array}$ \\
\hline c) Confiabilidade nas informações e relatórios contábeis & $\begin{array}{l}R 1, R 2, R 3, R 4, R 5, R 6, R 8, R 9, R 10, R 12, R 13, R 14, R 16 \\
\text { R17, R18, R20 }\end{array}$ \\
\hline d) Aumento da confiança dos stakeholders & $\mathrm{R} 1, \mathrm{R} 8, \mathrm{R} 17, \mathrm{R} 19$ \\
\hline e) Bom relacionamento entre os investidores & R10, R14 \\
\hline f) Auxiliar na tomada de decisões & $R 1, R 2, R 3, R 5, R 9, R 16, R 18, R 20, R 21, R 22$ \\
\hline g) Valorização dos negócios & $\mathrm{R} 5, \mathrm{R} 12, \mathrm{R} 13, \mathrm{R} 20$ \\
\hline h) Outros & \\
\hline
\end{tabular}

Fonte: Dados da Pesquisa

De acordo com as informações do Quadro 8, a opção "c" com dezesseis (16) e a "b" com quatorze (14) dos respondentes deram ênfase à alternativa que se refere à confiabilidade nas informações e relatórios contábeis, bem como evitar casos de fraudes e gestão inadequada.

A definição e importância do controle interno envolvem objetivos para a sua gestão como regra geral, entre eles a geração e a confiabilidade dos informes e relatórios contábeis, financeiros e operacionais adequados (ATTIE, 2006).

Uma boa estrutura de controle interno pode prevenir a ocorrência de fraudes. Assim como uma atitude administrativa sem uma preocupação preventiva, pode ser um fator definitivo para a essência de fraudes e ou concepção de um conjunto empresarial transigente com atos complacentes e de desordem (PEREIRA, 2009).

São diversos os aspectos dos controles internos que desempenham importância para as boas práticas da governança corporativa. Desta forma, observa-se a frequência das escolhas dos profissionais participantes da pesquisa, estão em concordância com a teoria, já que a relação entre governança e controle interno tende a trazer maior confiabilidade, valorização, auxiliar na tomada de decisão de uma empresa, bem como evitar erros e fraudes.

A última questão da pesquisa, fez menção aos princípios da governança corporativa. A pergunta aos profissionais da área contábil foi, se eles entendiam que esses princípios apresentavam ou não vantagem competitiva para o mercado financeiro. Todos os respondentes optaram pela resposta "sim" e, complementaram com os comentários apresentados no Quadro 9. 


\section{Gestãoe \\ Desenvolvimento}

e-ISSN: 2446-6875

p-ISSN: $1807-5436$

Quadro 9 - Vantagens Princípios de Governança Corporativa

\begin{tabular}{|l|l|}
\hline Respondentes & \multicolumn{1}{c|}{ Comentários } \\
\hline R1 & $\begin{array}{l}\text { É inegável que a empresa/entidade que adote os princípios da GP tem maior chance de se manter no } \\
\text { marcado por mais tempo e de melhor remunerar os stakeholders, logo, tem vantagem competitiva. }\end{array}$ \\
\hline R2 & $\begin{array}{l}\text { Tem maior segurança interna e aos stakeholders. Na análise de um terceiro sem conhecimento técnico, } \\
\text { pode ser insignificante. }\end{array}$ \\
\hline R3 & $\begin{array}{l}\text { Possuem controles internos que indicam com segurança os resultados da empresa, permitindo maior } \\
\text { agilidade na identificação dos indicadores precisos frente a uma tomada de decisão. }\end{array}$ \\
\hline R7 & $\begin{array}{l}\text { Com certeza, pois empresa que optam por adotar este princípios, tem objetivos específicos e estão } \\
\text { dispostas a trabalhar com ética e zelo. }\end{array}$ \\
\hline R15 & $\begin{array}{l}\text { A Governança corporativa nas empresas, em geral, é implantada para atender normas e requisitos de } \\
\text { instituições financeiras ou de investimentos, que, por sua vez, buscam segurança no lastro de suas } \\
\text { operações. }\end{array}$ \\
\hline R16 & $\begin{array}{l}\text { Adotando estes princípios a empresa reduz riscos e, consequentemente, gera credibilidade e confiança. } \\
\text { Estes são fatores que as fortalecem frente ao mercado financeiro. }\end{array}$ \\
\hline R17 & $\begin{array}{l}\text { Mostra para o público interno e externo as boas práticas adotadas pela empresa, agregando valor ao } \\
\text { empreendimento. }\end{array}$ \\
\hline R18 & Porque é uma empresa organizada \\
\hline R22 & $\begin{array}{l}\text { Trazem maior confiança e credibilidade, tanto para as pretensões da empresa quanto da possibilidade } \\
\text { de atrair investidores. }\end{array}$ \\
\hline
\end{tabular}

Fonte: Dados da Pesquisa

Os princípios básicos, bem como os seus conceitos estabelecidos pelo IBGC - Instituto Brasileiro de Governança Corporativa (2009) colaboraram para o crescimento e desenvolvimento da organização, com o intuito de agregar transparência e confiabilidade.

Considerando os elementos obtidos por meio das respostas recebidas, verificou-se que todos os vinte e dois (22) respondentes da pesquisa tem a percepção da importância dos controles internos e das vantagens para as empresas com a adoção dos princípios da governança corporativa.

Na próxima seção são apresentadas as considerações finais desta pesquisa.

\section{CONSIDERAÇÕES FINAIS}

Algumas décadas atrás, as pessoas se tornavam empresários para suprir a necessidade de uma região ou até mesmo cultural. Com o passar do tempo a necessidade dos mercados evoluiu e junto com a globalização veio a pressão da competitividade e, com ela, surgiram leis, normas, convenções e princípios. Assim, as organizações deparam-se com preocupação em comprovar a ética e transparência dos negócios para a sociedade em geral. Diante disto, as empresas viram-se pressionadas a se adequarem a procedimentos e controles internos que demonstrem prevenção de erros, bem como fraudes. Com isso, passou-se a exigir novas necessidades quanto ao perfil do administradores, empresários e dos profissionais da área contábil. 
A partir dessas mudanças, como também com o aumento da complexidade das organizações, entendeu-se que os controles internos trazem importância para o conjunto das boas práticas da governança corporativa, com objetivo de gerar resultados positivos para as instituições, para todas as suas partes interessadas e o mercado financeiro.

Desta forma, este estudo teve como objetivo geral: analisar a percepção dos profissionais da área contábil em relação à importância do controle interno no contexto das boas práticas de governança corporativa. A partir das respostas recebidas, constatou-se que todos os vinte e dois (22) respondentes da pesquisa compreendem que as empresas que adotam os princípios da governança corporativa, ou seja, a prática de transparência, equidade, prestação de contas e responsabilidade corporativa, podem obter vantagens competitivas.

Além disso, observou-se que os respondentes, compreendem que devido às mudanças de mercado passaram a necessitar conquistar cada vez mais confiança nas suas informações contábeis. Em função disso, a inclusão do controle interno e a adoção da governança corporativa vem conquistando o seu espaço dentro das empresas, como uma ferramenta que demonstre confiança, transparência, responsabilidade em seus negócios, bem como auxilia gestores no processo de tomada de decisão. Percebeu-se, também, que os respondentes da pesquisa têm um entendimento semelhante à fundamentação teórica apresentada, no que diz respeito aos conceitos de governança corporativa e de controle interno, ou seja, os pesquisados possuem uma visão ampla referente a sua aplicabilidade.

Assim, foi possível responder a questão problema dessa pesquisa: Qual a percepção dos profissionais da área contábil do Vale do Rio dos Sinos/RS em relação à importância do controle interno no contexto das boas práticas de governança corporativa? Verificou-se que os respondentes percebem que existe relação com a importância do controle interno no contexto das boas práticas de governança corporativa. E que essa relação contribui de diferentes maneiras, pois as empresas que possuem controle de suas informações contábeis e adotam a governança corporativa, transmitem confiabilidade aos seus stakeholders, bem como ao mercado financeiro com a apresentação dessas informações com princípios de ética, através de transparência, equidade, prestação de contas e responsabilidade corporativa.

Este estudo não tem a pretensão de esgotar o tema pesquisado, em razão de existirem limitações do estudo, sobretudo pela amostra limitada, o que restringe os resultados ao grupo estudado. Outra limitação a ser considerada é que, por se tratar de um tema novo para alguns profissionais, isso pode ter restringido a participação em alguns respondentes. Como tema de pesquisas futuras, sugerese a ampliação da amostra, para analisar a importância e a prática do controle interno no contexto da governança corporativa para profissionais em diferentes regiões do Brasil, com a finalidade de conferir as percepções dos profissionais perante a diversidade cultural do país. 


\section{Gestãoe \\ Desenvolvimento}

e-ISSN: 2446-6875

p-ISSN: $1807-5436$

Deste modo, finaliza-se essa pesquisa com satisfação, pois estudar este tema com certeza trouxe contribuições para a pesquisadora bem como para o meio acadêmico. Espera-se que em pouco tempo todas as empresas e seus os profissionais da área contábil possam ampliar a percepção da importância dos controles internos e entender os benefícios das boas práticas da governança corporativa.

\section{REFERÊNCIAS}

AICPA - American Institute of Certified Public Accountants / Instituto Americano dos Contadores Públicos Certificados. Sobre AICPA. Disponivel em: <http://www.aicpa.org/About/Pages/About.aspx>. Acesso em: 02 jan. 2017.

ATTIE, William. Auditoria: Conceitos e Aplicações. 3. Ed. São Paulo: Atlas, 2006.

BEUREN, Ilse Maria (org). Como Elaborar Trabalhos Monográficos em Contabilidade: Teoria e Prática. 3. ed. São Paulo: Atlas, 2008.

COMISSÃO DE VALORES MOBILIÁRIOS. Recomendações da CVM sobre Governança Corporativa. Cartilha de Governança. 2002. Disponivel em: <http://exame.abril.com.br/rede-de-blogs/investidor-em-acao/files/2011/04/cartilha-CVM-Governan\%C3\%A7a-Corporativa.pdf>. Acesso em: 04 dez. 2016.

COMITÊ DE PRONUNCIAMENTOS CONTÁBEIS - CPC OO. Estrutura Conceitual para Elaboração e Divulgação de Relatório Contábil-Financeiro. 2008. Disponivel em: <http://www.cpc.org.br/CPC/Documentos-Emitidos/Pronunciamentos/Pronunciamento?ld=80>. Acesso em: 29 jan. 2017.

CREPALDI, Silvio Aparecido. Auditoria Contábil: Teoria e Prática. 7. ed. São Paulo: Atlas, 2011.

FRANCO, Hilário; MARRA, Ernesto. Auditoria Contábil. 4. ed. São Paulo: Atlas, 2007.

GIL, Antônio Carlos. Como Elaborar Projetos de Pesquisa. 5. ed. São Paulo: Atlas, 2010.

IBGC - Instituto Brasileiro de Governança Corporativa. Código das Melhores Práticas de Governança Corporativa. 4. ed. São Paulo: IBGC, 2009.

JUNIOR, José Hernandez Perez. Auditoria de Demonstrações Contábeis: Normas e Procedimentos. 5. ed. São Paulo: Atlas, 2012.

MACHADO, Claudio Morais. A Importância dos Preceitos de Governança Corporativa e de Controle Interno Sobre a Evolução e a Internacionalização das Normas de Contabilidade e Auditoria. Porto Alegre: Scan - Editoração \& Produção Gráfica, 2011. 


\section{Gestãoe \\ Desenvolvimento}

e-ISSN: 2446-6875

p-ISSN: $1807-5436$

MALACRIDA, Mara Jane Contrera; YAMAMOTO, Marina Mitiyo. Governança Corporativa: Nível de Evidenciação das Informações e sua Relação com a Volatilidade das Ações do Ibovespa. R. Cont. Fin. USP, São Paulo. Edição Comemorativa. p. 65-79. Setembro de 2006. Disponível em: <http://www.scielo.br/pdf/rcf/ v17nspe/v17nspea06.pdf>. Acesso: 19 nov. 2016.

MATIAS-PEREIRA, José. Governança no Setor Público. São Paulo: Atlas, 2010.

NBC TA NORMAS BRASILEIRAS DE CONTABILIDADE - DE AUDITORIA INDEPENDENTE: NBC TA Estrutura Conceitual, NBC TA 200 a 810. Brasillia: Conselho Federal de Contabilidade, 2012.

OLIVEIRA, Djalma de Pinho Rebouças de. Governança Corporativa na Prática: Integrando Acionistas, Conselhos de Administração e Diretoria Executiva na Geração de Resultados. São Paulo: Atlas, 2006.

PEREIRA, Marcos Augusto Assi. Controles Internos e Cultura Organizacional: Como Consolidar a Confiança na Gestão dos Negócios. São Paulo: Saint Paul Editora, 2009.

PORTAL DE AUDITORIA. Gerenciamento de Riscos. Disponível em: <http://www.portaldeauditoria.com. br/auditoria-interna/Coso-Gerenciamento-de-Riscos-Corporativos.asp>. Acesso em: 29 dez. 2016.

RIBEIRO, Milton Nassau. Aspectos Jurídicos da Governança Corporativa. São Paulo: Quartier Latin, 2007.

ROSSETTI, José Paschoal; ANDRADE, Adriana. Governança Corporativa: Fundamentos, Desenvolvimento e Tendências. 3. ed. São Paulo: Atlas, 2007.

SCHERER, Fabiane Isabel; BURIOL, Juarez. Implantação do conselho de administração conforme as boas práticas da governança corporativa: estudo de caso na química LTDA. Revista Gestão e Desenvolvimento. v. 8, n.2, jul./dez. 2011. Disponivel em: <https://periodicos.feevale.br/seer/index.php/revistagestaoedesenvolvimento/issue/view/88> Acesso: 10 nov. 2019.

SILVA, André Luiz Carvalhal da. Governança Corporativa e Sucesso Empresarial: melhores práticas para aumentar o valor da firma. 2 ed. São Paulo: Saraiva, 2014.

SILVEIRA, Alexandre Di Miceli da. Governança Corporativa no Brasil e no Mundo: Teoria e Prática. Rio de Janeiro: Elsevier, 2010. 